\title{
Comportamento mecânico de solo argiloso estabilizado com resíduo de vidro pulverizado em moinho de alta energia e de bolas
}

\author{
Mechanical behavior of clay soil \\ stabilized with glass residue \\ powdered in high-energy \\ and ball mills
}

Carlos Eduardo Neves de Castro ${ }^{1}$, Roberto Rosselini Ferreira da Silva ${ }^{1}$, Lucas Fernandes Santos ${ }^{1}$, André Sales Mendes ', Cláudio Augusto de Paula Lima ${ }^{1}$, Consuelo Alves da Frota ${ }^{1}$

\footnotetext{
${ }^{1}$ Grupo de Pesquisa em Geotecnia - GEOTEC, Universidade Federal do Amazonas, 69080-900, Manaus, Amazonas, Brasil

e-mail: carlosnvscastro@gmail.com, obertor@hotmail.com, lucassantosplp@hotmail.com,andresalesmendes@gmail.com, cadpl.eng@gmail.com, cafrota@yahoo.com.br
}

\section{RESUMO}

A capital do Estado Amazonas apresenta dificuldades na construção de pavimentos devido à predominância superficial de argila em seu perfil geotécnico. Tal material mostra-se inadequado para a construção de subcamadas dessas estruturas urbanas. Avaliou-se, no presente estudo, o comportamento mecânico do solo argiloso típico de Manaus-AM na sua condição natural e quando misturado a 5\% de resíduos de vidro fragmentado em dois tipos de moinho (bolas e de alta energia), a fim de melhorar suas propriedades geotécnicas. Caracterizou-se o material "in natura" e suas composições alusivo às propriedades físicas (limite de liquidez, limite de plasticidade, granulometria e compactação), bem quanto a mineralogia do solo. Determinou-se, segundo o ensaio de cisalhamento direto e pelo critério de ruptura de Coulomb, a coesão e o ângulo de atrito interno do solo argiloso e das composições solo+5\% de vidro moído em moinho de bolas e solo+5\% vidro moído em moinho de alta energia. Os resultados mostraram que houve significativa melhora nas propriedades do solo regional quando aditivado pelo resíduo, do ponto de vista físico e mecânico, com ênfase quando da participação do material pulverizado no moinho de alta energia. Portanto, o resíduo de vidro apresenta potencial para ser utilizado como estabilizante granulométrico na execução de vias rodoviárias, além de uma alternativa ambiental para a disposição de tais materiais.

Palavras-chave: solo, resíduo de vidro, moinho de alta energia, coesão, ângulo de atrito

\section{ABSTRACT}

The capital of the Amazonas State presents difficulties in the construction of pavements due to the superficial predominance of clay in its geotechnical profile. This material is unsuitable for the construction of sublayers of these urban structures. In the present study, the mechanical behavior of the Manaus-AM typical clay soil was evaluated in its natural condition and when mixed with $5 \%$ of powdered glass waste processed in two types of mills (balls and high energy) in order to improve their geotechnical properties. The natural material and its compositions was characterized in relation to their physical properties (liquidity limit, plasticity limit, grain size and compaction) and mineralogical properties, as well as the natural soil mineralogy. According to the direct shear test and the Coulomb rupture criterion, the cohesion and the internal friction angle of the clay soil were determined, as well of the soil compositions with $5 \%$ of powdered glass processed in ball mill and $5 \%$ of powdered glass processed in high-energy mill. The results showed that there was a significant improvement in the regional soil properties when glass residue is added, both physically and mechanically, with emphasis on the participation of the powdered material processed in the high-energy mill. Therefore, the powdered glass has the potential to be used as granulometric stabilizer in roadways construction, which is an 
environmental alternative for the disposal of such materials.

Keywords: soil, glass residue, high-energy mill, cohesion, angle of friction

\section{INTRODUÇÃO}

O Serviço Geológico do Brasil, em 2010 [1], faz referência que 71\% do solo do Estado do Amazonas apresenta textura argilosa. Em particular, Bento e Frota (1998) [2] citam que a camada superficial da região urbana de Manaus é constituída por $62 \%$ de argila. Tal material possui, em regra, resistência não adequada e característica de difícil trabalhabilidade para o emprego em obras rodoviárias. A necessidade de substituí-lo pode implicar jazidas afastadas do local da construção, que oneram o custo da obra, tornando-se antieconômico. Menciona, ainda, a CPRM [1], que o solo granular presente no Amazonas corresponde a menos de $1 \%$ da sua área territorial. Frota et al. (2006) [3] aludem que Manaus e outros municípios do Amazonas convivem com uma histórica escassez de matéria-prima granular em superfície. Tal realidade tem como origem o intenso processo de intemperismo, que propiciou uma espessa camada de solo residual, tornando, muitas vezes, a obtenção do material rochoso impraticável economicamente.

Esse cenário requer atenção, em especial, na construção das subcamadas de um pavimento, visto que tecnicamente desejam-se materiais que apresentem boa resistência e baixa deformidade, propriedades encontradas, em geral, em solos granulares. Tais peculiaridades, somado a citada predominância de materiais finos superficiais [1,3] na região, impõem restrições técnicas quando da execução dos pavimentos regionais.

Por outro lado, quando o solo não evidencia os parâmetros geotécnicos prescritos em normas, há a necessidade de estabilizá-lo por processos químicos ou granulométricos, ou seja, misturá-los a aditivos ou a materiais, a fim de melhorar suas propriedades, como a resistência mecânica.

A literatura reporta sobre exemplos de solos estabilizados, particularmente composições com a presença de materiais moídos em alta energia. Bahmani et al. (2014) [4] observaram em seu trabalho aumento significativo na resistência à compressão simples (RCS), pela inserção de sílica moída a uma argila de alta plasticidade. Huan-Lin et al. (2012) [5] também notaram acréscimo de resistência na mistura de uma argila de baixa plasticidade com alumina, conforme os ensaios de RCS e CBR (Índice de Suporte Califórnia). Iranpour e Haddad (2016) [6] se utilizaram de materiais moídos como alternativa no tratamento de solos colapsíveis. No levantamento bibliográfico realizado por Ghasabkolaei et al. (2017) [7], estes verificaram que parte representativa do que vem sendo publicado na literatura, respeitante à estabilização de solos, comprovam a participação da sílica.

De outra forma, salienta-se que o vidro se constitui em uma das principais fontes de se obter a sílica. No entanto, até 2004, apenas $45 \%$ do vidro era reciclado no País, a despeito de poder ser $100 \%$ reciclável e em inúmeras vezes [8,9,10]. Isto posto, e considerando que a Política Nacional dos Resíduos Sólidos [11] recomenda estudos com vista a novas soluções para a adequada destinação final de resíduos, selecionou-se esse material $\left(\mathrm{SiO}_{2}\right)$, na condição moída, como aditivo na estabilização granulométrica do solo argiloso superficial típico de Manaus (SN). Resultaram as seguintes formulações: solo-5\% de vidro moído em moinho de bolas (SMB) e solo-5\% de vidro moído em moinho de alta energia (SMAE). Por conseguinte, cumpriu-se a motivação do trabalho em atender às demandas da engenharia e proporcionar alternativa às questões ambientais.

\section{MATERIAIS E MÉTODOS}

\subsection{Obtenção dos Materiais}

Coletou-se o solo natural de uma jazida (SN) localizada na camada superficial do Campus da Universidade Federal do Amazonas (UFAM), nas coordenadas $3^{\circ} 05^{\prime} 25.3^{\prime \prime} \mathrm{S} 59^{\circ} 58^{\prime} 04.4^{\prime \prime} \mathrm{W}$. Escolhe-se como aditivo o vidro proveniente de garrafas de refrigerante. Tais recipientes foram, inicialmente, higienizados, secos ao sol e, em seguida, desintegrados em partes menores no moinho de bolas com 12 esferas, operando 3500 ciclos.

Após esse procedimento, o produto foi passado na peneira $\mathrm{N}^{\circ} 40(0,42 \mathrm{~mm})$, tendo como finalidade, por se tratar de material cortante, trabalhar com tamanho mais seguro de partículas para execução dos ensaios, visto que a homogeneização do solo com o vidro requer manipulação manual. Na sequência, parte desse material passante na citada peneira foi triturado por 15 minutos em um moinho de alta energia, modelo SPEX Sample Prep 8000M (Figura 1a), numa razão bola-pó (solo) igual a 2:1. Tendo-se, assim, ao final do processamento, dois tipos de vidro moído: um peneirado e oriundo de moinho de bolas (Figura 1b), e outro proveniente de moinho de alta energia (Figura 1c). 


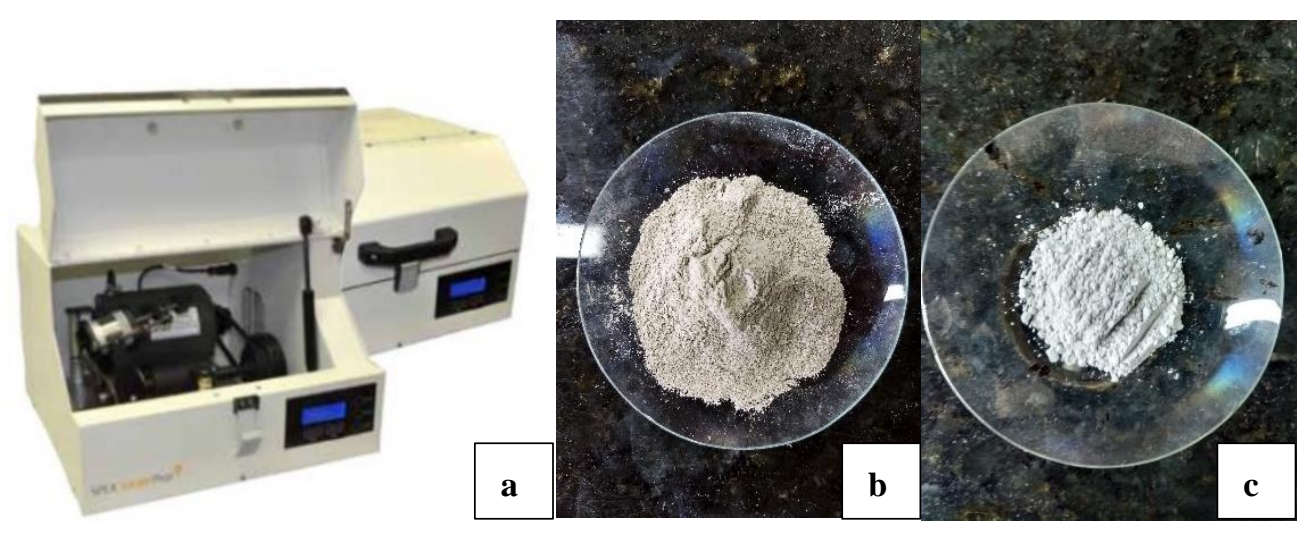

Figura 1: Moinho de alta energia(a), vidro triturado em moinho de bolas (b) e vidro pulverizado em moinho de alta energia (c).

\subsection{Caracterização Mineralógica, Geotécnica e Mecânica}

Determinou-se, inicialmente, por meio de difratometria de raio-X (DRX), a mineralogia do solo, utilizando o aparelho da marca SHIMADZU XRD6000, com radiação $\mathrm{CoK} \alpha$, monocromador de grafite e operado a 40 $\mathrm{kV}$ e $25 \mathrm{~mA}$. Destorroaram-se as amostras e, posteriormente, depositaram-se sobre uma lâmina de alumínio para análise pelo DRX, de acordo com irradiações angulares de $5^{\circ}$ a $60^{\circ}(2 \theta)$, com intervalo de $0,02^{\circ} 2 \theta$ a cada minuto.

Igualmente se examinou o material natural e as composições (SMB e SMAE) pelas recomendações da norma NBR 6457:2016 [12], que trata de amostras de solo para os seguintes ensaios geotécnicos: granulometria (NBR 7181:2016) [13], limite de liquidez (NBR 6459:2016) [14], limite de plasticidade (NBR 7180:2016) [15], massa específica dos grãos (NBR 6508:1984) [16] e compactação (NBR 7182:2016) [17]. Além disso, encontrou-se a granulometria do vidro moído.

Referente ao comportamento mecânico,executou-se o ensaio de resistência ao cisalhamento (ASTM D 3080-11) [18] em uma prensa de cisalhamento (Figura 2a), à tensão controlada, tendo sido determinado o ângulo de atrito interno e a coesão, nas condições últimas e residuais. Os corpos de prova (Figura 2b) para os citados testes acompanharam o grau de compactação em torno de $100 \% \pm 2 \%$.
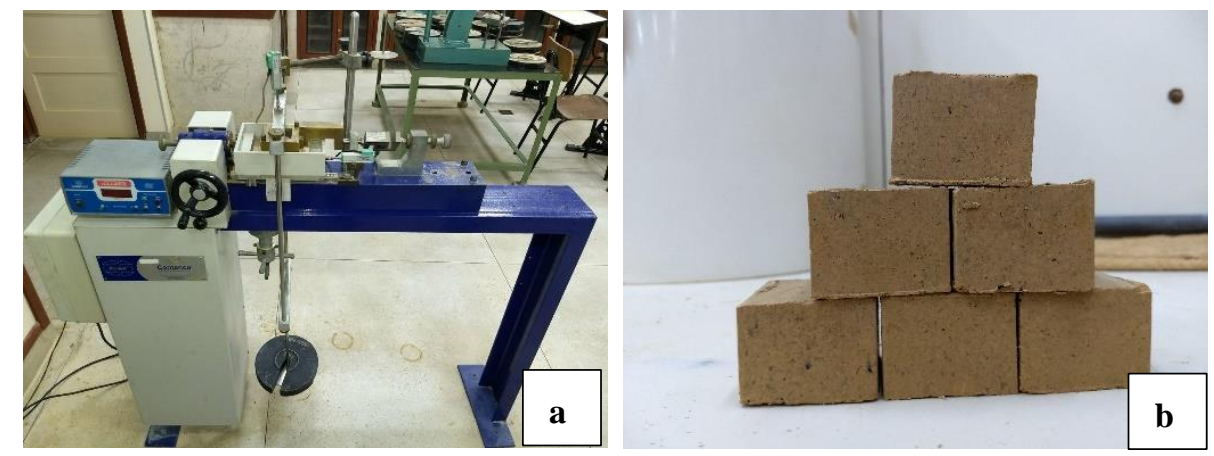

Figura 2: Prensa de cisalhamento direto (a) e corpos de prova (b).

\section{RESULTADOS}

\subsection{Características Físicas e Mineralógicas}

Os valores para o solo (SN) mostraram o limite de liquidez de $80,27 \%$ e o limite de plasticidade igual a 40,29\%, resultando em um índice de plasticidade (IP) de 39,98\%, portanto, classificado como alta plasticidade [19]. Para a composição com adição de 5\% de vidro moído em moinho de bolas (SMB), registrou-se $64,52 \%$ e $36,01 \%$ para o limite de liquidez e o limite de plasticidade, respectivamente. Obteve-se, 
dessa forma, um índice de plasticidade (IP) de 28,51\%, o que representa uma redução de $28,69 \%$ em relação ao SN. Consoante ao solo com a inserção de $5 \%$ de vidro moído em moinho de alta energia (SMAE), resultou o limite de liquidez igual a $60 \%$ e o limite de plasticidade de 35,33\%. Logo, um índice de plasticidade (IP) de $24,67 \%$, a saber, com valor $38,29 \%$ inferior ao IP do solo natural.

A granulometria do solo (SN) e das misturas (SMB e SMAE), indicadas na Figura 3, classificaram-se quanto a textura como materiais argilo-siltoso mal graduado e muito uniforme [19]. Em particular, o solo natural explicitou $23,87 \%$ de silte, $72,95 \%$ de argila e 3,18\% de areia. A adição do resíduo de vidro suscitou apenas uma redução de finos (silte + argila) para a formulação SMB (92,90\%) e a composição SMAE $(93,31 \%)$.

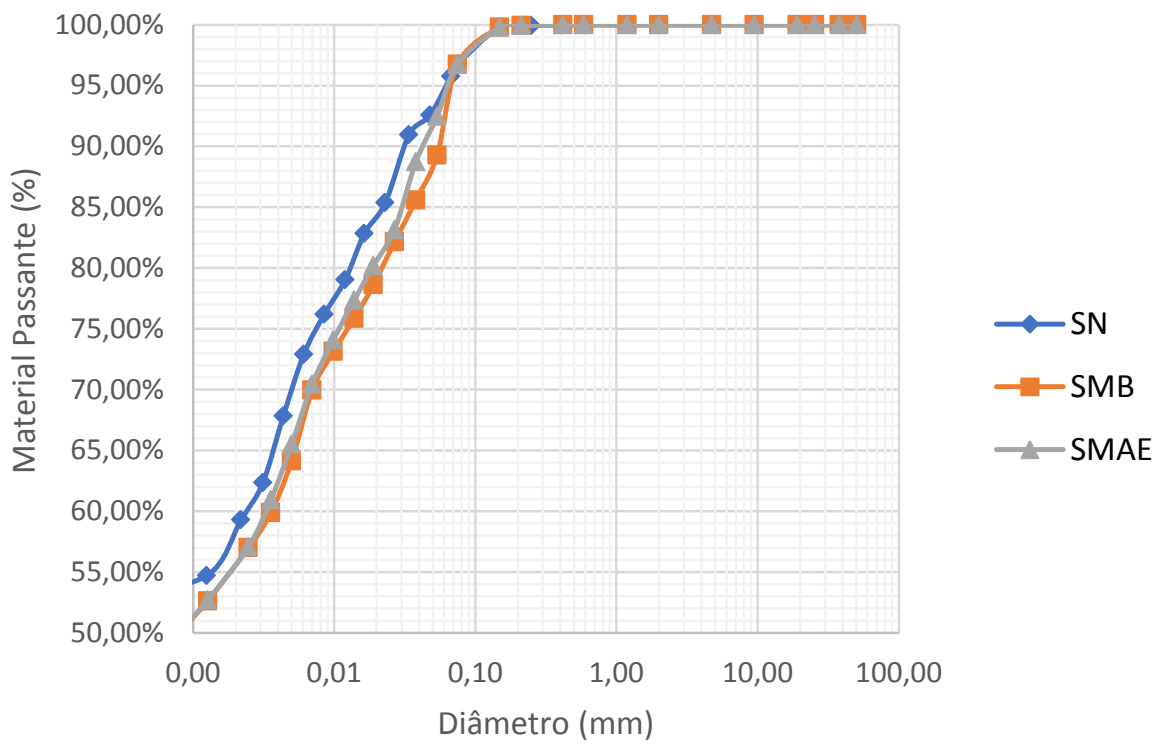

Figura 3: Curva granulométrica do solo natural e composições (SMB e SMAE).

O conjunto dos resultados da granulometria e dos limites de Atterberg tipificou o solo natural como MH (silte inorgânica de alta plasticidade) e A-7-5 (solo argiloso), pelas classificações SUCS e a AASHTO [19], respectivamente. A adição do vidro não alterou as referidas classificações, porém, ressalta-se a redução do IP das composições. Evidenciou-se também no solo natural, por meio da difratometria de raio - X (Figura 4), picos dos minerais caulinita $(\mathrm{K})$, halloysita $(\mathrm{Hl})$, goethita $(\mathrm{Go})$, anatásio (An) e hematita $(\mathrm{Ht})$. Esta assembleia mineral é típica dos solos da região de Manaus. Demonstra-se, assim, que o material natural é caulinítico. Verifica-se, igualmente, um percentual de ferro, posto que se constatou a participação dos minerais hematita e goethita (óxidos de ferro).

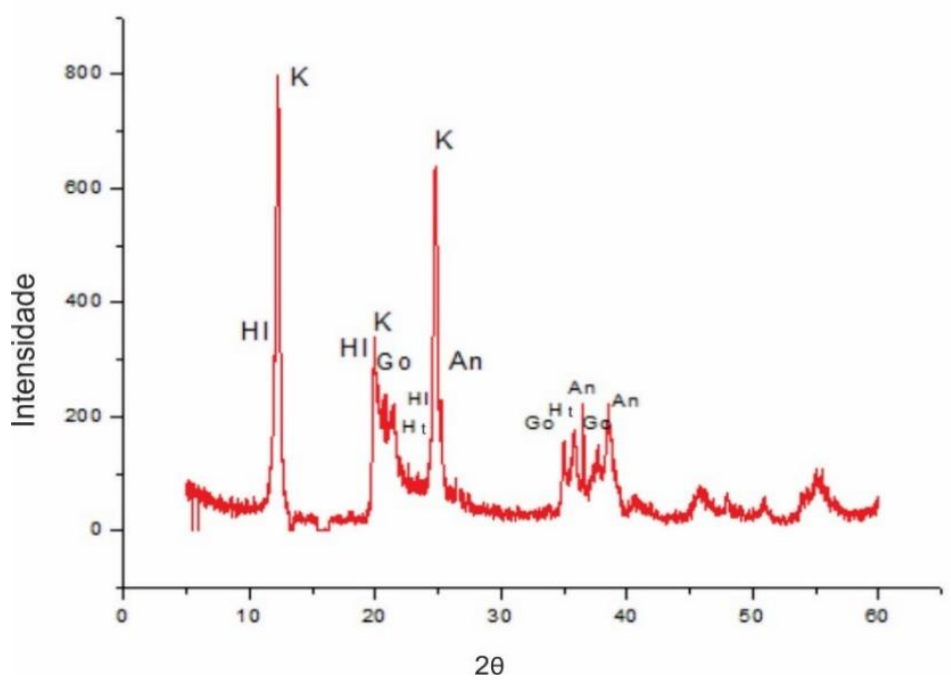

Figura 4: Difratometria do solo natural. 
Por fim, determinou-se a granulometria do vidro pulverizado em moinho de bolas (MB) e de alta energia (MAE) (Figura 5), que revelou, para ambos os aditivos, a classificação como uma areia siltosa fina, embora, com distinta participação da fração areia, ou seja, 72,49\% e 43,76\% alusivas ao resíduo MB e MAE, respectivamente. Salienta-se, além disso, que material processado MAE expôs maior porcentagem da fração siltosa $(31,24 \%)$ e argilosa (25\%), aproximadamente o dobro do encontrado no vidro triturado MB, a saber, $16,17 \%$ e $11,34 \%$, respectivamente. Constata-se, ainda, o material MB com uma textura muito uniforme e mal graduada, ao passo que MAE demonstra uma leve descontinuidade, logo, mais bem graduada.

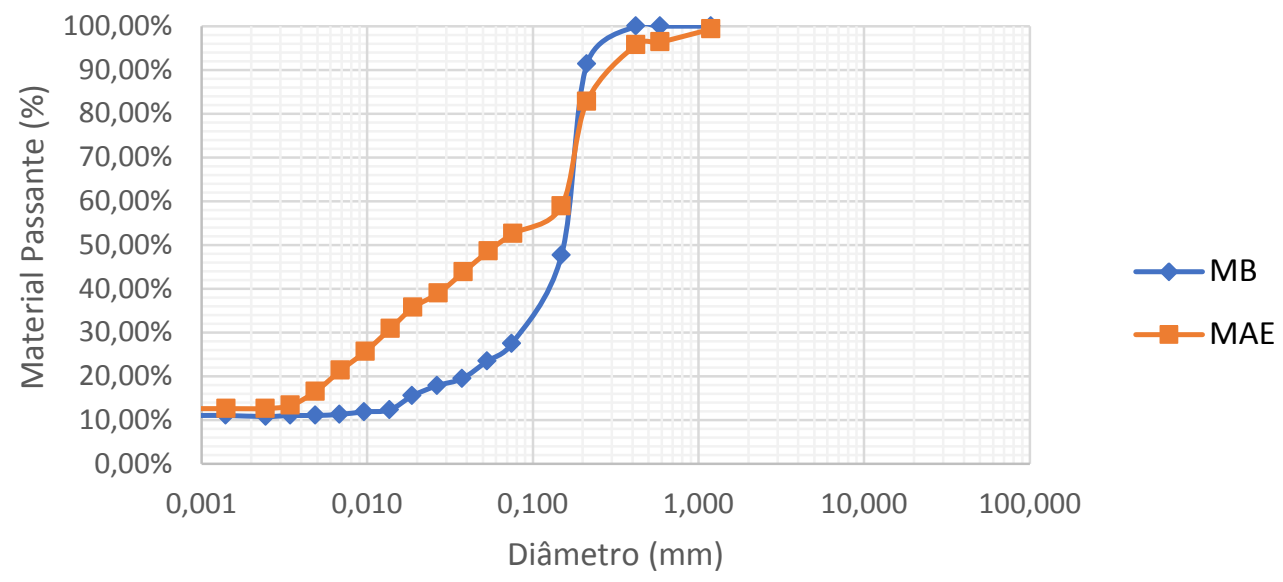

Figura 5: Granulometria do vidro pulverizado em moinho de bolas (MB) e em moinho de alta energia (MAE).

\subsection{Compactação}

As curvas de compactação do solo natural (SN) e composições (SMB e SMAE) são apresentadas na Figura 6. Referente ao material "in natura" a regressão polinomial forneceu uma umidade ótima de 33,8\% e um peso específico aparente seco máximo igual a $15,0 \mathrm{kN} / \mathrm{m}^{3}$. Quando adicionado a fração de $5 \%$ do resíduo de vidro proveniente do moinho de bolas, houve um incremento de $0,67 \%$ no valor deste parâmetro, resultando em $15,1 \mathrm{kN} / \mathrm{m}^{3}$. Por sua vez, a umidade ótima apontou redução, saindo de 33,8\% para o valor de $32,68 \%$. No caso da composição solo-resíduo de vidro em moinho de alta energia (SMAE), esta evidenciou um aumento de $2 \%$ no peso específico seco máximo e uma diminuição de 2,5\% na umidade ótima. Esta formulação registrou referente à mistura $\mathrm{SMB}$, um acréscimo de $1,32 \%$ no peso específico e uma redução na umidade ótima para 31,30\%. Portanto, o subproduto, notadamente quando presente na composição SMAE, indicou benefícios à densificação do solo argiloso (SN). Bahmani et al. (2014) [4], estudando uma argila orgânica de alta plasticidade, comprovaram que ao adicionar sílica nanométrica à mistura solo-cimento, o peso específico diminuiu e a umidade ótima aumentou. No entanto, chamam a atenção para o fato de que, na literatura, o desempenho esperado é o inverso, condizente com o observado na presente pesquisa.

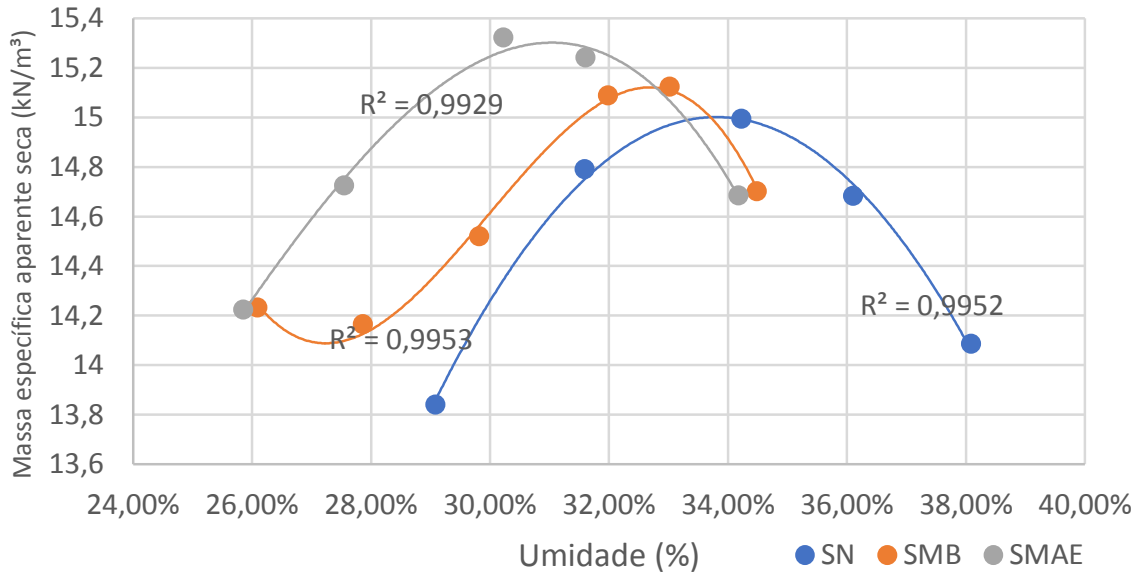

Figura 6: Curvas de compactação de solo natural e composições (SMB e SMAE). 
Ressalta-se que, após a determinação dos mencionados parâmetros de compactação, realizou-se a moldagem dos corpos de prova com o controle do grau de compactação. Este parâmetro exerce fundamental importância nos experimentos com amostras deformadas uma vez que, os corpos de prova devem apresentar densidades em torno daquelas determinadas nos ensaios de compactação. Na Tabela 1 expõem-se os valores dos graus de compactação que se encontram dentro da faixa desejável e prevista de $100 \% \pm 2 \%$.

Tabela 1: Parâmetros de moldagem dos corpos de prova.

\begin{tabular}{l|c|c|c|c|c|c|c|c|c}
\hline & \multicolumn{3}{|c|}{ SN } & \multicolumn{3}{c|}{ SMB } & \multicolumn{3}{c}{ SMAE } \\
\hline & $\mathrm{w}$ & $\begin{array}{c}\gamma_{\text {dmáx }} \\
\left(\mathrm{g} / \mathrm{cm}^{3}\right)\end{array}$ & $\begin{array}{c}\text { GC } \\
\%\end{array}$ & $\begin{array}{c}\mathrm{w} \\
\%\end{array}$ & $\begin{array}{c}\gamma_{\text {dmáx }} \\
\left(\mathrm{g} / \mathrm{cm}^{3}\right)\end{array}$ & $\begin{array}{c}\text { GC } \\
\%\end{array}$ & $\begin{array}{c}\mathrm{w} \\
\%\end{array}$ & $\begin{array}{c}\gamma_{\text {dmáx }} \\
\left(\mathrm{g} / \mathrm{cm}^{3}\right)\end{array}$ & $\begin{array}{c}\text { GC } \\
\%\end{array}$ \\
\hline CP1 & 33,19 & 15,13 & 100,89 & 31,82 & 15,28 & 101,21 & 31,51 & 15,28 & 99,90 \\
\hline CP2 & 33,74 & 14,90 & 99,30 & 32,14 & 15,23 & 100,90 & 30,56 & 15,40 & 100,68 \\
\hline CP3 & 34,29 & 14,98 & 99,90 & 33,11 & 15,11 & 100,11 & 30,99 & 15,18 & 99,24 \\
\hline
\end{tabular}

Legenda: $\mathrm{w}=$ umidade $\gamma_{\mathrm{dmáx}}=$ peso específico aparente seco máximo $\mathrm{GC}=$ grau de compactação

\subsection{Cisalhamento direto}

Os gráficos das Figuras 7 a 9 correspondem às curvas tensão cisalhante x deformação para solo natural (SN), solo+5\% de vidro moído em moinho de bolas (SMB) e solo+5\% de vidro moído em moinho de alta energia (SMAE), respectivamente. Para obtenção de cada curva moldaram-se, pelo menos, 3 corpos de prova (CP1, CP2 e CP3), com as dimensões de $5 \mathrm{~cm}$ de lado e altura igual a 3,60 cm. Os parâmetros de moldagem dessas amostras (peso específico aparente seco máximo e umidade ótima) e os graus de compactação (GC) podem ser verificados na Tabela 1. Os corpos de prova CP1, CP2 e CP3 correspondem as tensões normais de 49,05 $\mathrm{kPa}, 98,1 \mathrm{kPa}$ e $147,15 \mathrm{kPa}$, respectivamente.

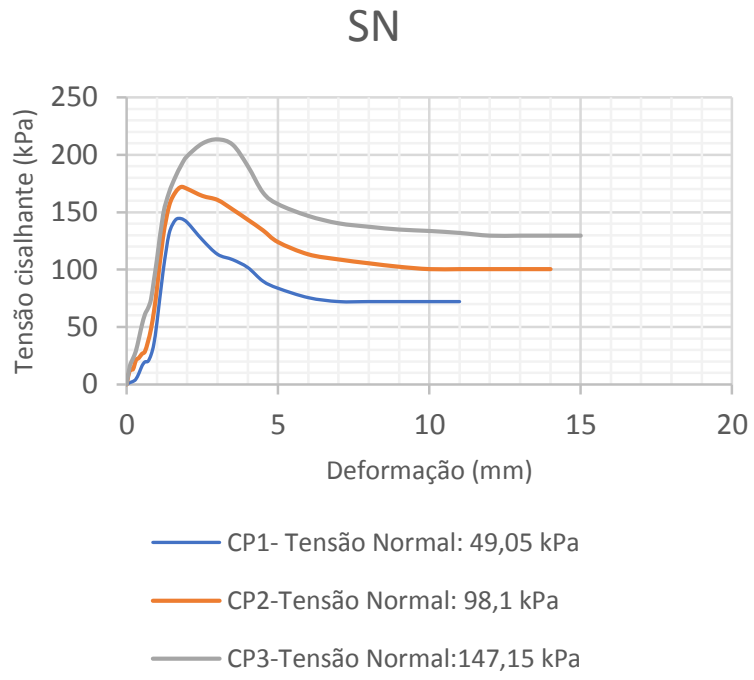

Figura 7: Tensão Cisalhante x Deformação (SN). 


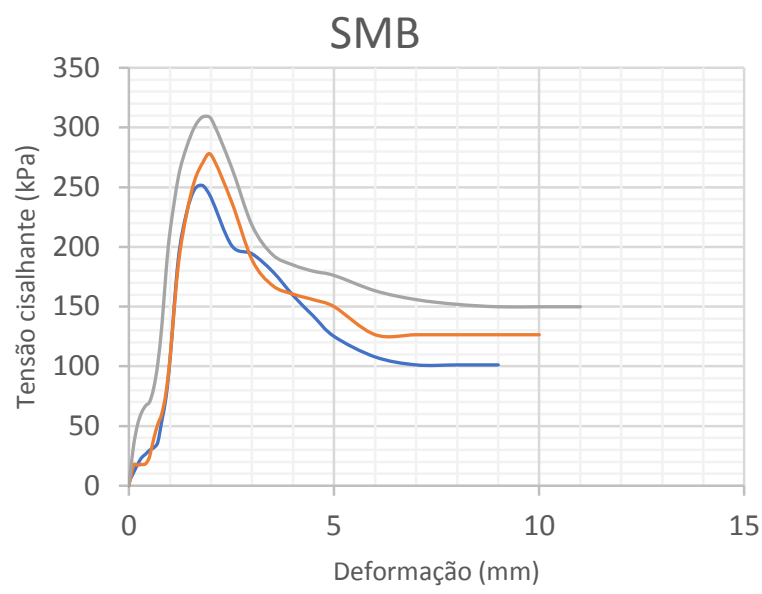

Figura 8: Tensão Cisalhante x Deformação (SMB).

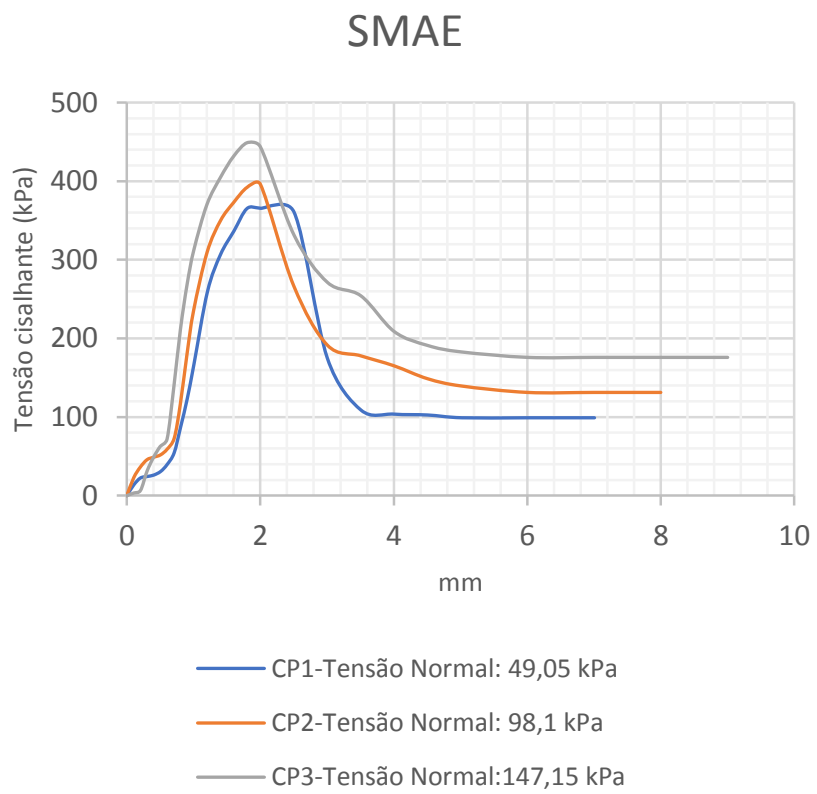

Figura 9: Tensão Cisalhante x Deformação (SMAE).

Examinando o comportamento para a tensão normal (TN) de 49,05 kPa (Figuras 7-9), o solo SN e as misturas SMB e SMAE apresentaram uma deformação de $1,80 \mathrm{~mm}$ para a tensão última de cisalhamento (TUC). Todavia, enquanto o solo atingiu essa deformação com uma TUC de 144,32 kPa, as formulações SMB e SMAE necessitaram de valores superiores iguais a 74,11\% (251,28 kPa) e 153\% $(365,52 \mathrm{kPa})$, respectivamente. Relativo à tensão normal de 98,1 kPa (Figuras 7-9), nas condições últimas, as deformações resultaram 1,80 mm (SN) e 2,00 mm (SMB e SMAE). Embora as composições tenham demonstrado deformações sensivelmente superiores, lembra-se que o solo (SN) obteve a deformação de 1,80 mm com uma tensão última de cisalhamento de $172 \mathrm{kPa}$, ao passo que, esse parâmetro para a composição SMB ocorreu em 
uma TUC com valor $61,14 \%$ superior $(277,17 \mathrm{kPa})$. Da mesma forma, a formulação SMAE necessitou de uma TUC 130,29\% maior (396,10 kPa) para alcançar a referida deformação.

Ao analisar os resultados em seu estado último (Figuras 7-9), submetido à tensão normal de 147,15 $\mathrm{kPa}$, constata-se deformação para o solo natural ( $\mathrm{SN}$ ) de 3,0 $\mathrm{mm}$ e 1,80 $\mathrm{mm}$ para as formulações. Ressalta-se que o solo (SN), para uma TUC de 213,43 kPa, a deformação já atingia um valor 66,67\% maior respeitante às composições, quando estas eram submetidas a TUC de 308,92 kPa e 448,99 $\mathrm{kPa}$, respectivamente. Logo, comprova-se a capacidade dos aditivos na melhoria do solo natural.

Atenta-se, igualmente, que o solo e as composições indicaram comportamento geral esperado, isto é, à medida que a tensão normal cresceu, concomitantemente acompanharam a tensão de cisalhamento última (TUC) e a residual (TCR) (Figuras 7-9). Outrossim, certifica-se que os valores da TUC e TCR evidenciaram resultados superiores relativos àqueles explicitados para o solo natural e as misturas (Tabela 2). Confrontando-se os dados constantes na Tabela 2, tem-se para o solo "in natura" (SN), uma queda de resistência de 50\% (CP1), 41,61\% (CP2) e 39,28\% (CP3). No caso da composição SMB, de forma similar, se constata uma redução de resistência de $59,74 \%$ (CP1), $45,93 \%$ (CP2) e 51,48\% (CP3). Para a formulação SMAE, nota-se análogo desempenho com um decréscimo de resistências iguais a 72,89\% (CP1), 66,85\% (CP2) e $60,83 \%$ (CP3).

Tabela 2: Tensões últimas e residuais de cisalhamento.

\begin{tabular}{c|c|c|c|c|c|c|c}
\hline & & \multicolumn{2}{|c|}{ SN } & \multicolumn{2}{c|}{ SMB } & \multicolumn{2}{c}{ SMAE } \\
\hline & TN $(\mathrm{kPa})$ & TUC $(\mathrm{kPa})$ & TCR $(\mathrm{kPa})$ & TUC $(\mathrm{kPa})$ & TCR $(\mathrm{kPa})$ & TUC $(\mathrm{kPa})$ & TR $(\mathrm{kPa})$ \\
\hline $\mathrm{CP} 1$ & 49,05 & 144,32 & 72,13 & 251,28 & 101,167 & 365,52 & 99,07 \\
\hline $\mathrm{CP} 2$ & 98,1 & 172,00 & 100,427 & 277,176 & 126,443 & 396,098 & 131,31 \\
\hline $\mathrm{CP} 3$ & 147,15 & 213,43 & 129,587 & 308,926 & 149,87 & 448,99 & 175,8865 \\
\hline
\end{tabular}

Prosseguindo a análise (Tabela 2), respectivo ao solo "in natura" (SN), tem-se: a) para a tensão normal de 49,05 kPa, valores superiores da TCU iguais a 74,11\% (SMB) e 153,27\% (SMAE). Comparando entre si essas duas formulações, tem-se que o material oriundo do moinho de alta energia resultou valor $45,46 \%$ maior; b) consoante à tensão normal de $98,1 \mathrm{kPa}$, as composições obtiveram ganhos de resistência iguais a $61,14 \%$ e $130,29 \%$, respectivamente. Confrontando somente as duas misturas, o desempenho da SMAE foi $42,9 \%$ superior; c) para a tensão normal de $147,15 \mathrm{kPa}$, a composição SMB incrementou a resistência ao cisalhamento em 44,74\%, enquanto a formulação SMAE em 110,37\%. Analisando exclusivamente as misturas (SMB e SMAE), o resultado alusivo à composição SMAE novamente mostrou-se maior em $45,34 \%$.

De forma semelhante, ao correlacionar os resultados após a ruptura do solo (tensão residual) alusivos ao solo natural (SN) (Tabela 2), obteve-se: a) fixando a tensão normal de 49,05 $\mathrm{kPa}$, a TCR demonstrou ganhos percentuais de 40,24\% (SMB) e 37,34\% (SMAE); b) para a tensão normal de $98,1 \mathrm{kPa}$, aponta valores superiores iguais a $25,91 \%$ (SMB) e 30,76\% (SMAE); e c) quando a tensão normal alcançou 147,15 $\mathrm{kPa}$, houve acréscimo da resistência residual em 15,66\% (SMB) e 37,5\% (SMAE). Sublinha-se o resultado da mistura SMAE com valor 17,33\% superior ao da formulação SMB.

Conhecidas as tensões cisalhantes, traçaram-se as envoltórias de Coulomb, ou seja, os gráficos tensão cisalhante $\mathrm{x}$ tensão normal, a fim de se obter a coesão e ângulo de atrito para o solo SN e formulações (SMB e SMAE), conforme a tensão última (Figura 10) e residual (Figura 11). 


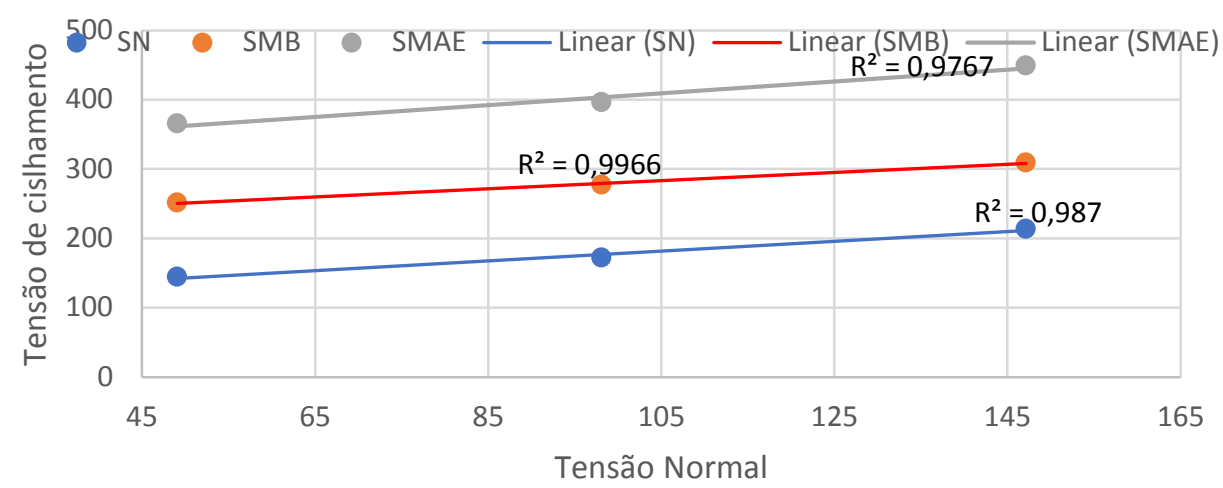

Figura 10: Envoltória de Coulomb para tensão cisalhante última.

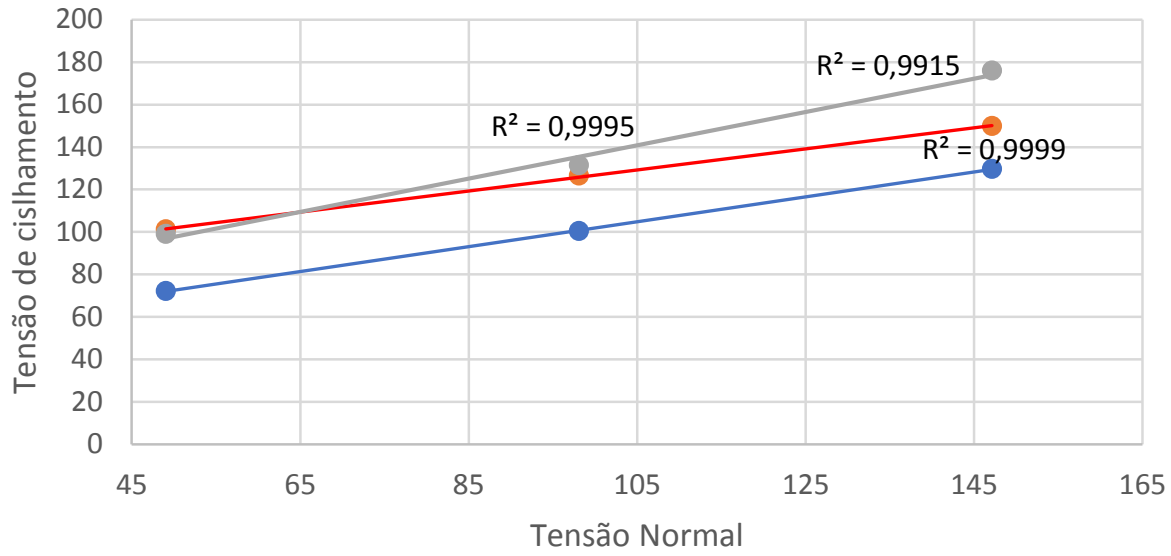

Figura 11: Envoltória de Coulomb para tensão cisalhante residual.

Para o estado de tensão cisalhante última (Figura 10), segundo a regressão linear, pôde-se notar que o solo natural apresentou coesão de $107,48 \mathrm{kPa}$ e ângulo de atrito de $35,16^{\circ}$. Quando adicionado $5 \%$ de vidro moído em moinho de bolas, a composição (SMB) mostrou um aumento na coesão, passando de 107,48 kPa para $229,49 \mathrm{kPa}$, e em termos percentuais igual a 113,52\%. Quanto ao ângulo de atrito, houve uma redução de $13,42 \%$, chegando a um valor igual a $30,44^{\circ}$. A formulação com vidro moído em moinho de alta energia (SMAE), mais uma vez, indicou os melhores resultados, ou seja, uma coesão de $320,06 \mathrm{kPa}$. Este extraordinário valor situa-se em torno do triplo da coesão encontrada para o solo natural (SN) e 39,4\% maior respeitante à formulação $\mathrm{SMB}$, além disso, foi a mistura que apontou o maior ângulo de atrito $\left(40,39^{\circ}\right)$.

No caso do estado de tensão cisalhante residual (Figura 11), como esperado, teve-se uma redução na coesão e no ângulo de atrito do solo "in natura" (SN), a saber, 43,26 kPa e 30,3 , respectivamente, o que equivale, em termos percentuais a um decréscimo de $59,45 \%$ na coesão e de $13,82 \%$ no ângulo de atrito interno. Alusivo à mistura SMB, verificou-se o maior valor da coesão $(77,12 \mathrm{kPa})$ e o menor ângulo de atrito $\left(26,4^{\circ}\right)$, indicativos ao solo natural $(\mathrm{SN})$. Consoante a composição SMAE, esta assinalou menor resultado da coesão comparado a formulação $\operatorname{SMB}(58,61 \mathrm{kPa})$. No entanto, ressalta-se que, ainda assim, é o melhor resultado para este parâmetro, respeitante ao solo "in natura", com um valor superior igual a 35,48\%. No caso do ângulo de atrito, este registrou um decrescimento de 5,77\%, chegando ao valor de $38,06^{\circ}$.

Bahmani et al. (2014) [4] verificaram que a resistência à compressão simples (RCS) da composição solo-cimento, com valor de $515 \mathrm{kPa}$, alcançou $1611 \mathrm{kPa}$ com a inserção de apenas $0,4 \%$ de nano sílica, em termos percentuais um acréscimo de $212,81 \%$. Enfatizam que o solo "in natura", que registrava uma RCS de cerca de $300 \mathrm{kPa}$, ao ser aditivado com esse nano material sua resistência aumentou 437\%. Os autores observaram ainda incremento de resistência ao solo "in natura" de 45,4\%, à medida que se diminuiu o tamanho das partículas, resultado igualmente atingido neste trabalho. 


\section{CONCLUSÕES}

A adição de 5\% do resíduo de vidro não alterou a textura e a classificação do solo natural (argilo-siltoso), conforme a AASHTO e a SUCS. Porém, constatou-se significativa redução nos limites de Atteberg e, consequentemente, no índice de plasticidade, com destaque para a composição com o vidro pulverizado em moinho de alta energia (SMA). Sublinha-se, também, que nos parâmetros de compactação, pelo aumento do peso específico máximo e a redução da umidade ótima, o resíduo triturado em alta energia se consolidou como o melhor aditivo para melhoria das características físicas do solo "in natura".

No tocante ao desempenho mecânico, novamente, ambas as formulações foram significativamente superiores ao solo natural, sendo a mistura SMAE a que demonstrou o melhor resultado, creditado ao tamanho de suas partículas, segundo corrobora a literatura.

Em vista do exposto, a adição de resíduo de vidro ao solo argiloso assinalou melhorias em suas propriedades, do ponto de vista físico e mecânico, uma vez que diminuiu a plasticidade do solo e aumentou de maneira significativa a densidade e a resistência ao cisalhamento, o que faz desse material uma alternativa para estabilização granulométrica ao mesmo tempo que comtempla às questões ambientais.

\section{AGRADECIMENTOS}

Ao Conselho Nacional de Desenvolvimento Científico e Tecnológico (CNPq) pela concessão da bolsa ao primeiro autor.

\section{BIBLIOGRAFIA}

[1] CPRM - Serviço Geológico do Brasil. Geodiversidade do Estado do Amazonas. Programa Geologia do Brasil - Levantamento da Geodiversidade. Relatório técnico 2010. Manaus, AM, 2010. Disponível em: http://www.cprm.gov.br/publique/media/Geodiversidade_AM.pdf

[2] BENTO, A. H., FROTA, C. A. "Mapeamento Geotécnico da Área Urbana de Manaus em seu Aspecto Ambiental", In: $4^{\circ}$ Congresso Brasileiro de Geologia de Engenharia Congresso Brasileiro de Geotecnia Ambiental, pp. 71-77, Rio de Janeiro - RJ, 1998.

[3] FROTA, C. A., MELO, D. M., NUNES, F. R. G., "Análise do Comportamento Mecânico de Misturas Asfálticas com Resíduo Processado da Construção Civil”, In: V Jornadas Luso-Brasileiras de Pavimentos: Políticas e Tecnologias, Andit, p.15, Recife-PE, Jul. 2006. Disponível em: http://www.andit.org.br/vjornada/Trabalho\%20Final/Trabalho\%20V-048.pdf

[4] BAHMANI, S. H., HUAT, B. B. K., ASADI, A., et al., "Stabilization of residual soil using $\mathrm{SiO}_{2}$ nanoparticles and cement", Construction and Building Materials, v. 64, pp. 350-359, Ago. 2014. Disponível em: https://doi.org/10.1016/j.conbuildmat.2014.04.086

[5] HUAN-LIN L., HSIAO D., LIN D., LIN C., "Cohesive soil stabilized using sewage sludge ash/cement and nano aluminum oxide", International Journal of Transportation Science and Technology, v.1, n. 1, Mar.2012. Disponível em: https://doi.org/10.1260/2046-0430.1.1.83

[6] IRANPOUR, B., HADDAD, A. "The influence of nanomaterials on collapsible soil treatment", Engineering Geology, v. 205, pp. 40-53, 2016.

[7] GHASABKOLAEI, N., CHOOBBASTI, A. J., ROSHAN, N., et al., "Geotechnical properties of the soils modified with nanomaterials: A comprehensive review", Archives of Civil and Mechanical Engineering, v. 17, n. 3, Mai. 2017. Disponível em: https://doi.org/10.1016/j.acme.2017.01.010

[8] BNDES - Banco Nacional do Desenvolvimento, Considerações sobre a indústria do vidro no brasil, Setorial, n. 26, pp. 101-138, Rio de Janeiro - RJ, set. 2007. Disponível em: https://www.bndes.gov.br/SiteBNDES/export/sites/default/bndes_pt/Galerias/Arquivos/conhecimento/bnset/s et2605.pdf

[9] IPEA (2012) - Instituto de Pesquisa Econômica Aplicada, Diagnóstico dos Resíduos Sólidos Urbanos. Relatório de Pesquisa 2012. Brasília, DF: 2012 p.82. Disponível em: http://www.ipea.gov.br/agencia/images/stories/PDFs/relatoriopesquisa/121009_relatorio_residuos_solidos_ur banos.pdf

[10] ABIVIDRO - Associação Brasileira das Indústrias de Vidro. Reciclagem de vidro no Brasil. Disponível em: https://www.abividro.org.br/reciclagem-abividro/reciclagem-no-brasil 
[11] BRASIL. Lei Federal no 12.305, de 2 de agosto de 2010. Institui a Política Nacional de Resíduos Sólidos; altera a Lei no 9.605, de 12 de fevereiro de 1998; e dá outras providências. Diário Oficial da União, Brasília, 2 ago. 2010.

[12] NBR 6457:2016 - Amostras de solo - preparação para ensaios de compactação e ensaio de caracterização.

[13] NBR 7181:2016 - Solo - Análise Granulométrica

[14] NBR 6459:2016 - Solo - Determinação do Limite de Liquidez

[15] NBR 7180:2016 - Solo - Determinação do limite de Plasticidade

[16] NBR 6508:1984 - Solo - Massa Específica Real dos Grãos.

[17] NBR 7182:2016 - Solo - Ensaio de Compactação.

[18] ASTM - AMERICAN SOCIETY FOR TESTING AND MATERIALS. ASTM D 3080-11: Standard Test Method for Direct Shear Test of Soils Under Consolidated Drained Conditions. USA, 2011.

[19] DAS, B. M., Fundamentos de engenharia geotécnica. 7 ed. São Paulo, Cengage Learning, 2014.

\section{ORCID}

Carlos Eduardo Neves de Castro

https://orcid.org/0000-0003-2764-0967

Roberto Rosselini Ferreira da Silva

https://orcid.org/0000-0002-8542-3947

André Mendes Sales

https://orcid.org/0000-0002-4470-3475

Lucas Fernandes Santos

https://orcid.org/0000-0002-9581-4028

Cláudio Augusto de Paula Lima

https://orcid.org/0000-0002-1644-6512

Consuelo Alves da Frota

https://orcid.org/0000-0002-1766-2823 